\title{
USE OF PUPILLOMETRY IN THE DIAGNOSIS OF STRESS IN PIGLETS TRANSPORTED IN A TROPICAL CLIMATE
}

\author{
Nítalo A. F. Machado ${ }^{1 *}$, , José A. D. Barbosa-Filho², João B. F. Souza-Junior³, \\ Geraldo L. B. Ramalho ${ }^{4}$, Michelle de O. M. Parente ${ }^{1}$
}

${ }^{1 *}$ Corresponding author. Center for Agrarian and Environmental Sciences - UFMA/ Chapadinha - MA, Brazil.

E-mail: nitalo.farias@ufma.br | ORCID ID: https://orcid.org/0000-0002-4967-2620

\begin{abstract}
KEYWORDS
animal transport, image analysis, animal welfare, precision livestock farming.
\end{abstract}

\begin{abstract}
The objective of this study was to evaluate the reactivity of the pupillary area (PA) as a non-invasive method for diagnosing stress in piglets submitted to transport. A total of 10 journeys were monitored and grouped according to the transport distance (15 and $75 \mathrm{~km})$. Were sampled 360 piglets $(25 \pm 3.8 \mathrm{~kg})$ to measure the PA, body temperature $(\mathrm{BT})$, and serum concentrations of cortisol and creatine kinase (CK). The micrometeorological characterization of the load was performed using enthalpy comfort index (ECI). It was possible to identify an increase of $19.32 \%\left(+18.91 \mathrm{~mm}^{2} ; P<0.001\right)$ in PA of piglets transported in shorter journeys $(15 \mathrm{~km})$, as well as the highest mean values of BT $(+1.24$ $\left.{ }^{\circ} \mathrm{C} ; P<0.001\right)$, cortisol $(+2.37 \mathrm{ng} / \mathrm{mL} ; P<0.001)$ and $\mathrm{CK}(+379 \mathrm{U} / \mathrm{L} ; P=0.025)$. In this study, high correlations of PA were observed with $r=0.922,0.900,0.842$ and 0.829 $(P<0.05)$ for cortisol and CK, BT and ECI of trailer, respectively. In conclusion, we state that PA reactivity is a physiological response for the diagnosis of stress of piglets transported. Further research will refine this technique in order to make this non-invasive acquisition method more practical and adaptable to different transport conditions.
\end{abstract}

\section{INTRODUCTION}

Transport is considered one of the most critical operations for animal welfare (Pinheiro et al., 2021). During transport, pigs are subjected to various stressors, such as mixing lots, deprivation of food and water, changes in the environment, vibrations and noise (Mota-Rojas et al., 2014; Benincasa et al., 2020). All with the potential to cause physiological and psychological stress (Faucitano, 2018; Tasse \& Molento 2019).

Although it is a routine practice among farms with multiple production sites (Rioja-Lang et al., 2019), the transport of piglets is a complex operation regarding animal welfare because it causes severe negative impacts through stress, pain, and suffering during the journey (Rocha et al., 2016), which leads to serious economic losses by reducing feed consumption at finishing stage (Mota-Rojas et al. 2014), dehydration and deaths on arrival (DOA) (Johnson et al. 2018).
Nowadays, stress monitoring techniques are often invasive and require animal restriction or specific training, like using iButton sensors (Pereira et al., 2018), radiotelemetry (De Jong et al., 1998), and salivary cortisol (Dalla-Costa et al., 2009). The use of a non-invasive method would facilitate routine in animal production systems and could provide better welfare conditions for animals during transport.

In this context, pupillometry presents itself as a useful tool for practical application, especially because the regulation of the pupillary area (PA) is controlled by the autonomous nervous system. Previous studies show that PA has shown to expand (mydriasis) as a consequence of mental effort and exposure to stressors in humans (Lempert et al., 2015) and in goats subjected to heat stress (Marques et al., 2018).

${ }^{1}$ Center for Agrarian and Environmental Sciences - UFMA/ Chapadinha - MA, Brazil.

2 NEAMBE - Department of Agricultural Engineering - DENA/ UFC/ Fortaleza - CE, Brazil.

${ }^{3}$ Department of Animal Science, UFC/ Fortaleza - CE, Brazil.

${ }^{4}$ Department of Industry, IFCE/ Fortaleza - CE, Brazil.

Area Editor: Héliton Pandorfi

Received in: 11-28-2020

Accepted in: 5-14-2021 
Pupillometry can be an important tool for precision livestock farming as it is a non-invasive method with the potential to monitor chronic stress in breeding systems. This technology can assist producers and transporters in decision making and transport planning in order to optimize production losses by monitoring the welfare state of animals.

In animal science, the use of pupillometry to evaluate the stress of animals is still incipient as far as the knowledge reaches, requiring further investigations. Therefore, the objective of this study was to evaluate the reactivity of the pupillary area as a non-invasive method for diagnosing stress in piglets submitted to transport.

\section{MATERIAL AND METHODS}

The experimental procedures in animals were performed according to the guidelines of the Animal Ethics Committee of the Federal University of Ceará and were approved by this committee with protocol number 9871250719/2019.

\section{Location and Logistics}

The journeys were performed under commercial conditions at a farm located in the municipality of Maracanaú - CE (354'46 "S 38 39'19 "W at 43m altitude), between the period from 16 to 28 July 2019 . A total of 10 journeys were monitored, 5 to the municipality of Maranguape - CE ( $3^{\circ} 51^{\prime} 50$ "S 38 $40^{\circ} 05^{\prime W}$ at $68 \mathrm{~m}$ altitude) and 5 to the municipality of Caridade - CE (409'19 "S $39^{\circ} 05^{\prime} 30$ "W at $144 \mathrm{~m}$ altitude), corresponding to distances of $15 \mathrm{~km}$ and $75 \mathrm{~km}$, respectively.

The transportation was performed in a Ford $®$ cargo 1519 truck, with a double-deck (two-story Triel® - HT model), containing six compartments $(2.92 \mathrm{~m}$ length $\times 2.4$ $\mathrm{m}$ width $\times 1 \mathrm{~m}$ height) per floor, totaling 12 compartments and a load capacity of 13 tons (Figure 1). The vehicle was not equipped with an air conditioning system, and the compartments did not contain any type of bedding or water supply system. The vehicle was not equipped with an air conditioning system, and the compartments did not contain a water supply system. Feeding was suspended only when the animals started to load and the density of the load during transport was $136 \mathrm{~kg} / \mathrm{m}^{2}$.

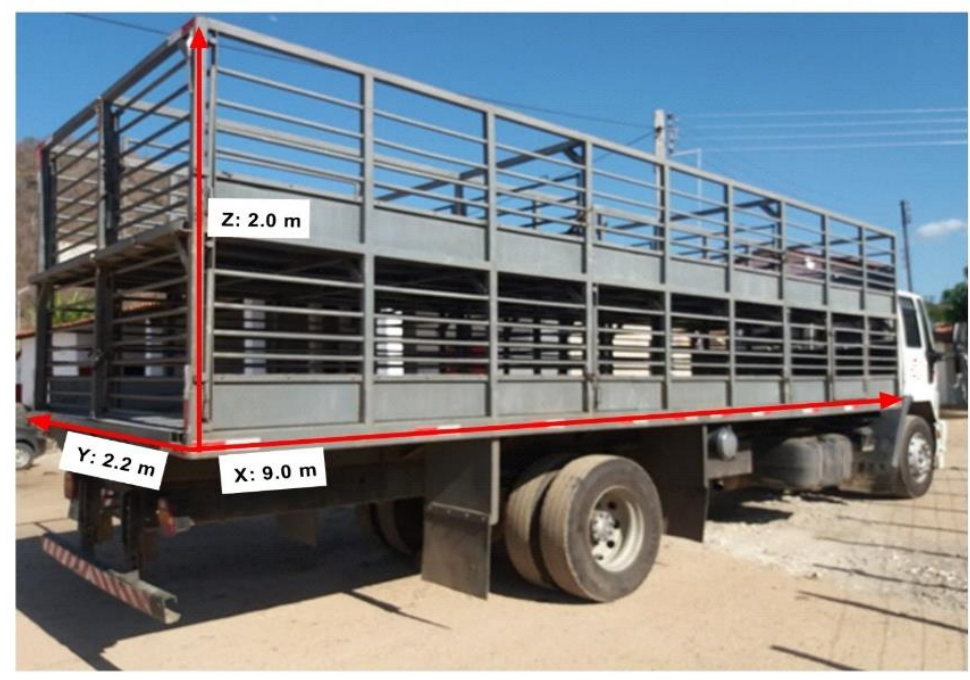

FIGURE 1. Trailer used to transport piglets.

The loading of piglets submitted to $75 \mathrm{~km}$ journeys started at 13:30 $\pm 8 \mathrm{~min}$. the animals were handled with flags during the loading procedure. Pre-molded loading ramps with a $30^{\circ}$ slope was used for the lower deck, and a metal ramp with 3 meters and $58^{\circ}$ slope for the upper deck. After loaded, the piglets were wetted randomly by a farm employee, using a hose as described by Pinheiro et al. (2020) and the average water used ( \pm SE) was $2,852 \pm 210$ liters per load.

The truck loading finished at 14: $20 \pm 10 \mathrm{~min}$, the of

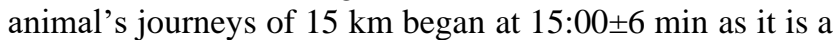
standard farm management practice where the study was conducted. The transportation time was $120 \pm 14 \mathrm{~min}$ and
$80 \pm 12 \mathrm{~min}$, respectively, for $75 \mathrm{~km}$ and $15 \mathrm{~km}$ journeys. The journeys were made on asphalt roads.

\section{Thermal parameters}

Twelve data loggers (Onset@, model U23-001 HOBO ${ }^{\circledR}$ Pro v2, with $\mathrm{TA} \pm 0.2^{\circ} \mathrm{C}$ and $\mathrm{RH} \pm 2.5 \%$ accuracy) were setted to measure temperature (TA) and relative air humidity $(\mathrm{RH})$ every $10 \mathrm{~min}$. The data loggers were distributed in the twelve truck trailer compartments, at the height of the animals, according to Machado et al. (2021a). The micrometeorological characterization of the load was performed with Enthalpy Comfort Index (ECI, $\mathrm{kJ} / \mathrm{kg}$ dry air) proposed by Rodrigues et al. (2011), estimated by [eq. (1)].

$$
\mathrm{ECI}=1.006 \times \mathrm{TA}+\frac{\mathrm{RH}}{\mathrm{Pb}} \cdot 10^{7.5 \times \mathrm{TA}(237.3+\mathrm{TA})^{-1}} \times(71.28+0.052 \times \mathrm{TA})
$$


Where:

TA: temperature $\left({ }^{\circ} \mathrm{C}\right)$;

RH: relative air humidity (\%);

$\mathrm{Pb}$ : local barometric pressure ( $\mathrm{mm} \mathrm{Hg}$ ).

\section{Animal's data acquisition}

A total of 2160 crossbred piglets (Large White $\mathrm{x}$ Landrace $x$ Duroc) at 7 weeks of age and average with an average body weight of $25 \pm 4.5 \mathrm{~kg}$ were transported. From these, a sub-sample of 360 animals (72 per journey) with an average body weight of $25 \pm 3.8 \mathrm{~kg}$ was randomly selected and identified with markings on the dorsal and auricular region in the farm pen $80 \pm 15$ min before loading.

The piglets were housed in all trailer compartments (3 per compartments). The protocol to register physiological variables was applied about $30 \pm 8 \mathrm{~min}$ after transport. Initially, the reactivity of the pupillary area (PA) of the piglets at the time of unloading, during the weighing of the piglets, that is, before being housed in the pens of the finishing farm, was evaluated.

Body temperature was collected prior to the piglet's containment, without physical interference. Then, the animals were held lightly and briefly (maximum $2 \mathrm{~min}$ ) in a supine position for blood collection to analyze the serum concentration of cortisol and creatine kinase, as previously described by Machado et al. (2020a). All samples were taken from each animal in $3 \pm 1 \mathrm{~min}$.

The measurement of PA was performed after the unloading of the piglet's, before the collection of the physiological variables. The animals were taken to an individual platform scale (Baltec Master ${ }^{\circledR} \mathrm{ACB}$, Araçatuba, SP, Brazil) containing a device for automatic image acquisition according to Lopes Neto et al., (2018).

The PA image acquiring equipment consists of a camera with a 16-megapixel resolution (Nikon ${ }^{\circledR}$ CoolPix B500 16MP Full HD, São Paulo, SP, Brazil), an Arduino® UNO system, a $5 \mathrm{~V}$ module and an ultrasonic sensor HCSR04. The ultrasonic sensors triggered the image capturing as they detected the presence of the animal emitting an electric pulse to the Arduino ${ }^{\circledR}$ microcontroller. The controller then sends a signal to the camera's USB input, triggering the image capture (Figure 2A).

The images were zoomed in, focusing on the orbital region (Figure 2B), and PA measurement was performed in the imageJ® software. Five images of each animal were selected and the eye perimeter was manually outlined to obtain the PA, as shown in Figure 2C. The software calibration was performed using a method adapted from Marques et al. (2018), using a reference scale of $5 \mathrm{~mm}$ in the cage of the individual platform scale.

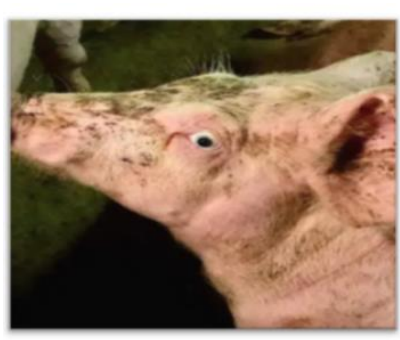

A

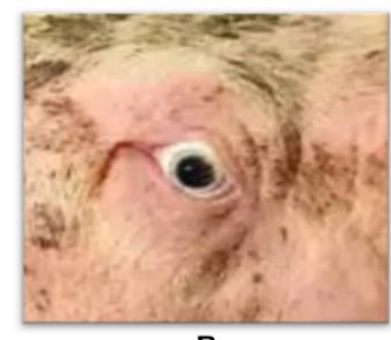

B

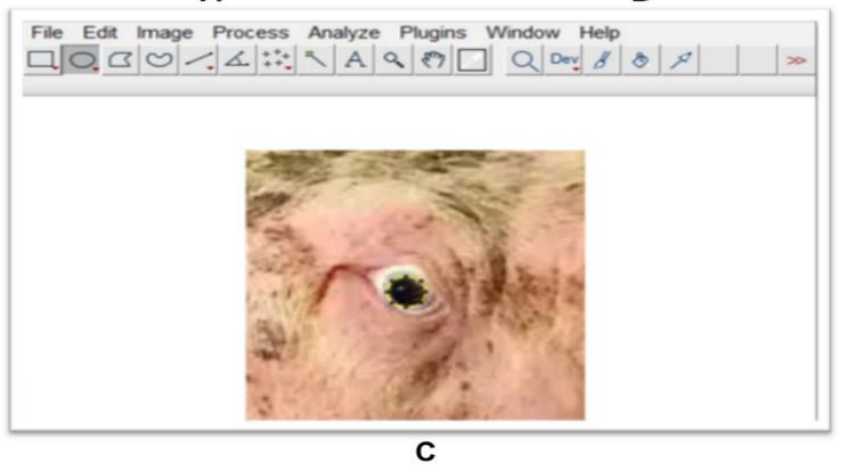

FIGURE 2. Image (A), zoom in the orbital region (B) and ImageJ interface, delimiting the perimeter of the pupil area.

Body temperature was obtained by thermal imaging from a thermographic camera (TiS10, Fluke, 4,800 pixels resolution), by adjusting the environmental temperature at the time of image recording, and emissivity of biological tissues $\varepsilon=0.98$ (Machado et al., 2021b). Thermal images were obtained with a fixed distance of $0.50 \mathrm{~m}$ between the animal and the observer (Soerensen et al., 2014), analyzed by SmartView 4.3 software. All thermal images were analyzed in the SmartView 4.3 software.

Blood samples of $10 \mathrm{~mL}$ were collected in the animals' jugular vein using hypodermic needles of $18 \times 38$ $\mathrm{mm}$ by a veterinarian, after the animals were restrained for further analysis of cortisol and creatine kinase (CK). This procedure was followed by hemostasis, to avoid any type of sequelae. Then the samples were stored in tubes (BD Vacutainers, Kasvi K50204S).

Cortisol determination was performed with an Elisa commercial kit (Neogen Corp. Lexington, KY, USA) with a microplate reader (BioTek $\operatorname{In}^{\circledR}$, ELx808 ${ }^{\mathrm{TM}}$, Winooski, VT, USA). CK was determined using the commercial kit (Creatine Kinase-SL, Sukisui Diagnostics) and CK serum concentrations were obtained by spectrophotometer (Konica Minolta ${ }^{\circledR}$, CM-3600A).

\section{Statistical Analyses}

The data obtained were analyzed by ANOVA using SAS ${ }^{\circledR}$ PROC GLIM (SAS Inst. Inc., Cary, NC) followed by comparisons of means with Tukey test $(P<0.05)$. The degree of relation between the studied variables $(P<0.05)$ was obtained based on Pearson's linear correlation coefficient (r) using the PROC CORR. 


\section{RESULTS AND DISCUSSION}

The piglets that were transported for $15 \mathrm{~km}$ showed higher pupillary area $(P<0.001)$ compared to animals transported for $75 \mathrm{~km}$, with an increase of $19.32 \%$. These animals also showed the highest serum concentrations of cortisol (+ $2.37 \mathrm{ng} / \mathrm{mL} ; P<0.001)$ and $\mathrm{CK}(+379 \mathrm{U} / \mathrm{L}$;
$P=0.025)$ and the highest body temperature $\left(+1.24{ }^{\circ} \mathrm{C}\right.$; $P<0.001$ ) when compared to piglets transported for $75 \mathrm{~km}$. It is important to note that we found a significant reduction in the heat contained in the trailer $(-5.24 \mathrm{~kJ} / \mathrm{kg}$ of dry air) for a $75 \mathrm{~km}$ journey when compared to $15 \mathrm{~km}$ journey (Table 1).

TABLE 1. Mean $( \pm$ SE) of the pupillary area, body temperature, serum concentrations of cortisol and creatine kinase of piglet's and enthalpy comfort index of trailer during transport.

\begin{tabular}{cccccc}
\hline Journeys & $\begin{array}{c}\text { Pupillary area } \\
\left(\mathrm{mm}^{2}\right)\end{array}$ & $\begin{array}{c}\text { Cortisol } \\
(\mathrm{ng} / \mathrm{mL})\end{array}$ & $\begin{array}{c}\text { Creatine kinase } \\
(\mathrm{U} / \mathrm{L})\end{array}$ & $\begin{array}{c}\text { Body temperature } \\
\left({ }^{\circ} \mathrm{C}\right)\end{array}$ & $\begin{array}{c}\mathrm{ECI}^{2} \\
(\mathrm{~kJ} / \mathrm{kg} \text { of dry air })\end{array}$ \\
\hline $15 \mathrm{~km}$ & $97.51 \pm 1.69^{\mathrm{a}}$ & $34.82 \pm 2.64^{\mathrm{a}}$ & $4367 \pm 86.15^{\mathrm{a}}$ & $40.34 \pm 0.78^{\mathrm{a}}$ & $83.50 \pm 1.28^{\mathrm{a}}$ \\
$75 \mathrm{~km}$ & $78.60 \pm 2.08^{\mathrm{b}}$ & $32.45 \pm 2.14^{\mathrm{b}}$ & $3988 \pm 54.47^{\mathrm{b}}$ & $39.10 \pm 0.83^{\mathrm{b}}$ & $78.26 \pm 1.80^{\mathrm{b}}$ \\
\hline $\mathrm{CV}(\%)$ & 7.96 & 8.04 & 16.47 & 4.02 & 6.60 \\
P value & $<0.001$ & $<0.001$ & 0.025 & $<0.001$ & 0.015 \\
\hline
\end{tabular}

Means followed by different letters (lines) are different from each other by the Tukey test at $5 \%$ significance. CV = coefficient of variation; ${ }^{1}$ Data transformed to $\log 10$ and ${ }^{2}$ Enthalpy Comfort Index.

The results show that the adverse effects of stress on piglets is reduced for higher journey. We attribute this to the fact that the longer transport duration allows a "rest period" with effect similar to a waiting time at the slaughterhouse (Haley et al., 2008). Thus, the piglets adapt to transport conditions (social and physical environment), reducing the impacts caused by loading (Goumon \& Faucitano, 2017).

This hypothesis is also supported by reduced heat in the trailer on longer journeys $(75 \mathrm{~km})$. According to SilvaMiranda et al., (2012) environments with ECI values above $80 \mathrm{~kJ} / \mathrm{kg}$ of dry air are favorable for the thermal stress of piglets. This suggests that the micrometeorological profile of longer trips was, on average, more favorable, possibly due to the lower need for heat and water vapor dissipation into the environment by the animals due to their greater thermal balance.

In a study carried out in Spain, Perez et al., (2002) concluded that pigs submitted to shorter trips (15 minutes) showed a more intense stress response (increases of 19.02 $\mathrm{mg} / \mathrm{mL}$ and $29.46 \mathrm{ng} / \mathrm{mL}$ of lactate and cortisol in the blood, respectively) and worse meat quality (reduction of 0.09 and 0.17 of the $\mathrm{pH}$ of Longissimus Thoracis and Semimembranosus and discoloration), in comparison with pigs submitted to longer journeys (3 hours), when they were immediately slaughtered on arrival at the slaughterhouse.

In this study, the pupillary area showed significant high positive correlations with other physiological responses and with the heat in the load (ECI). The linear correlation coefficients obtained for the serum concentrations of cortisol and creatine kinase, body temperature, and ECI were $\mathrm{r}=0.92,0.90,0.84$, and 0.82, respectively (Table 2 and Figure 3 ). These findings show the potential use of pupillometry in precision livestock farming, specifically the reactivity of pupillary area as a diagnosis of stress, including commercial animal transport conditions.

TABLE 2. Correlations of the pupillary area with the enthalpy comfort index, body temperature, serum concentrations of cortisol and creatine kinase.

\begin{tabular}{lcccc}
\hline \multirow{2}{*}{ Item } & \multicolumn{3}{c}{ Linear Models } & \multicolumn{2}{c}{$P$-value } \\
\cline { 2 - 4 } & $\mathrm{a}$ & $\mathrm{b}$ & $\mathrm{r}$ & 0.031 \\
Enthalpy Comfort Index & 0.824 & 15.160 & 0.829 & 0.018 \\
Body temperature & 0.086 & 31.192 & 0.842 & $<0.001$ \\
Cortisol & 0.243 & 12.346 & 0.922 & $<0.001$ \\
Creatine kinase $^{1}$ & 17.812 & 2519.000 & 0.922 \\
\hline
\end{tabular}

${ }^{1}$ Data transformed to $\log 10$ 


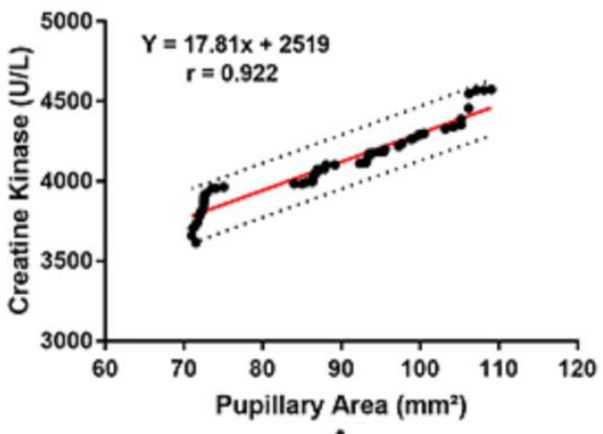

A

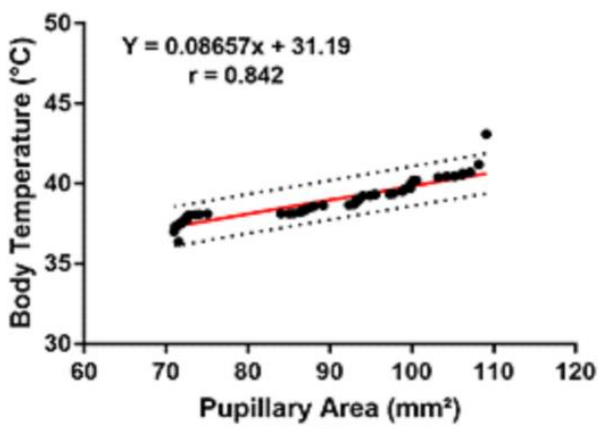

C
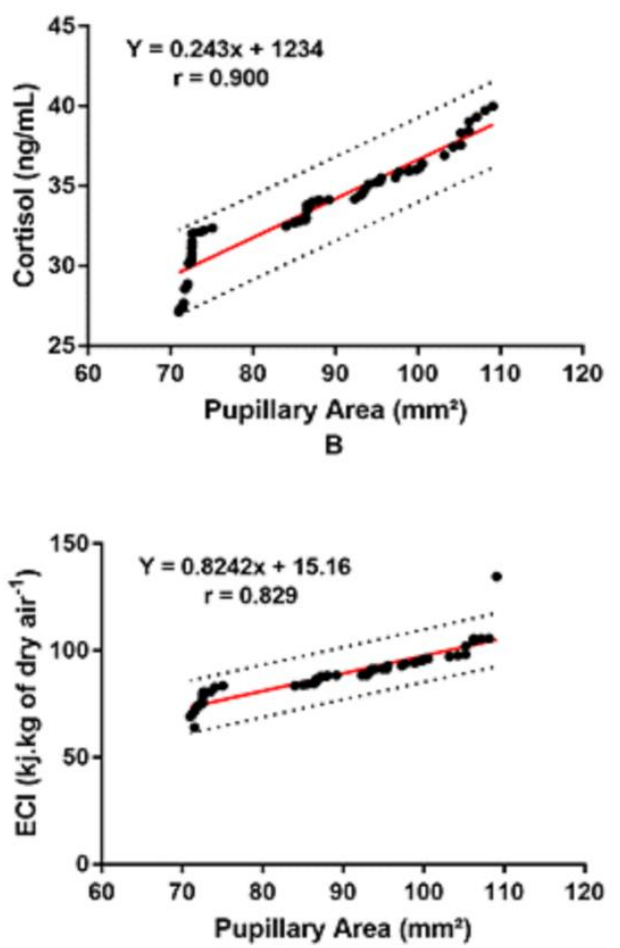

D

FIGURE 3. Diagrams of dispersion between pupillary area with serum concentration of $\mathrm{CK}^{1}$ (A), cortisol (B), body temperature (C) and enthalpy comfort index (D). ${ }^{1}$ Data transformed to $\log 10$

Pupillary area (PA) gives physiological response for the diagnosis of stress od piglets submitted to transportation. It was possible to detect that piglets subjected to short trips experienced more intense stress. These animals presented a pupil area dilation of $18.91 \mathrm{~mm}^{2}$, about $19.32 \%$ greater than the PA of piglets subjected to longer journeys (Table 1).

These findings show the relationship between the PA the stress. The reason for this is that PA regulation is associated with immediate activation of the neuroaxis when facing stress, which leads to the activation of the sympathetic system of autonomic nervous system by the production and release of noradrenaline in the mediations of the locus coeruleus (Lempert et al., 2015).

The stress causes activation of the autonomic nervous system, increasing the serum levels of cortisol and CK in piglets subjected to shorter trips, also showing an increase in adrenocortical activity in these animals (Table 1). These parameters suggest greater physical stress (higher CK values), related to fatigue and muscle exhaustion, possibly due to the handling of piglets (Goumon \& Faucitano, 2017).

Therefore, due to the stress during transport, the activation of the sympathetic system of the autonomic nervous system and the peripheral nervous system occurred, resulting in physiological changes (McDougall et al., 2015), which includes pupillary mydriasis (Laeng et al., 2012). Furthermore, factors related to human-animal interaction in the loading and unloading of pigs (Mota-Rojas et al., 2020).

In a bioclimatic chamber study, Marques et al., (2018) analyzed the pupillary dilation of crossbred goats and reported a significant PA increase of $37 \%$ with a $4^{\circ} \mathrm{C}$ rise in the temperature and a high correlation with linear correlation coefficient $(\mathrm{r}=0.99)$, indicating a direct relationship with the activation of sensitive mechanisms of heat loss to the maintenance of the animals' homeothermy.

In this study, we identified PA correlations from 0.82 to 0.92 with physiological stress indicators, especially with serum CK concentration (Table 2 and Figure 2). The CK is considered an important biochemical marker of muscle fatigue (Miles et al., 2008) used for measuring muscle exhaustion during pig transport (Correa et al., 2014). These results show that PA is a potentially tool in the description of the sympathetic system adaptations of the autonomic nervous system of piglets under stress conditions.

Although, the pupillary area can be used as a variable for measuring physiological responses in a non-invasive way and with a reasonable degree of accuracy in the studied conditions. Further research is needed to refine the technique in order to achieve a more practical and adaptable acquisition method to commercial transport conditions.

\section{CONCLUSIONS}

The reactivity of the pupil area is a useful physiological response for the diagnosis of stress in piglets during transport. However, further studies are needed to develop more refined image acquisition methods and image processing techniques to make the method more practical and adaptable to the farm and for animal transportation.

\section{ACKNOWLEDGMENTS}

We appreciate the support of the Coordination of Superior Level Staff Improvement (CAPES, Portuguese: Coordenação de Aperfeiçoamento de Pessoal de Nível Superior). 


\section{REFERENCES}

Benincasa NC, Sakamoto KS, Silva IJO, Lobos CMV (2020) Animal welfare: impacts of pre-slaughter operations on the current poultry industry. Journal of Animal Behaviour and Biometeorology 8(2): 104-110. DOI: http://dx.doi.org/10.31893/jabb.20014

Correa JA, Gonyou H, Torrey S, Widowski T, Bergeron R., Crowe T, Laforest JP, Faucitano L (2014) Welfare of pigs being transported over long distances using a potbelly trailer during winter and summer Animals 4:200213. DOI: http://dx.doi.org/10.3390/ani4020200.

Dalla-Costa OA, Ludke JV, Coldbelle A, Kich JD, Costa MJRP, Faucitano L. Peloso JV, Roza DD (2009) Efeito do manejo pré-abate sobre alguns parâmetros fisiológicos em fêmeas suínas pesadas Ciência Rural 39:852-858. DOI: http://dx.doi.org/10.1590/S0103-84782009000300033

De Jong IC, Ekkel ED, Van De Burgwal JA, Lambooij E, Korte SM, Ruis MAW, Koolhaas JM, Blokhuis HJ (1998) Effects of straw bedding on physiological responses to stressors and behavior in growing pigs Physiology \& Behavior 64:303-310. DOI: http://dx.doi.org/10.1016/s0031-9384(98)00066-3

Faucitano L (2018) Preslaughter handling practices and their effects on animal welfare and pork quality Journal of Animal Science 96:728-738. DOI: https://doi.org/10.1093/jas/skx064

Goumon S, Faucitano L (2017) Influence of loading handling and facilities on the subsequent response to preslaughter stress in pigs Livestook Science 200:6-13. DOI: https://doi.org/10.1016/j.livsci.2017.03.021

Haley C, Dewey CE, Widowski T, Poljak Z, Friendship R (2008) Factors associated with in-transit losses of market hogs in Ontario in 2001 Canadian journal of veterinary research 72: 377-384. Available:

https://www.ncbi.nlm.nih.gov/pmc/articles/PMC2568040/

Johnson JS, Aardsma MA Duttlinger AW, Kpodo KR (2018) Early life thermal stress: Impact on future thermotolerance, stress response, behavior, and intestinal morphology in piglets exposed to a heat stress challenge during simulated transport Journal Animal Science 96: 1640-1653. DOI: https://doi.org/10.1093/jas/sky107

Laeng B, Sirois S, Gredebäck G (2012) Pupillometry: A window to the preconscious? Perspectives on Psychological Science 7:18-27. DOI: https://doi.org/10.1177/1745691611427305

Lempert KM, Chen YL, Fleming SM (2015) Relating pupil dilation and metacognitive confidence during auditory decision-making PLoS One 10: 1-12. DOI: https://doi.org/10.1371/journal.pone.0126588

Lopes-Neto JP, Marques JI, Furtado DA, Lopes FFM, Borges VP, Araújo TGP (2018) Pupillary stress index: A new thermal comfort index for crossbred goats Revista Brasileira de Engenharia Agrícola e Ambiental, 22, 866871. DOI: https://doi.org/10.1590/1807-

1929/agriambi.v22n12p866-871.
Marques JI, Lopes-Neto JP, Nascimento JWB do, Talieri IC, Medeiros GR de, Furtado DA (2018) Pupillary dilation as a thermal stress indicator in boer crossbred goats maintained in a climate chamber Small Ruminant Research 158:26-29. DOI: https://doi.org/10.1016/j.smallrumres.2017.11.013

McDougall SJ, Münzberg H, Derbenev AD, Zsombok A (2015) Central control of autonomic functions in health and disease. Frontiers in Neuroscience 8:440-442. DOI: https://doi.org/10.3389/fnins.2014.00440

Miles MP, Andring JM, Pearson SD, Gordon LK, Kasper C, Depner CM, Kidd JR (2008) Diurnal variation, response to eccentric exercise, and association of inflammatory mediators with muscle damage variables. Journal of Applied Physiology 104:451-458. DOI: https://doi.org/10.1152/japplphysiol.00572.2007

Machado NAF, Martin JE, Barbosa-Filho JAD, Dias CTS, Pinheiro DG, Oliveira KPL de, Souza-Junior JBF (2021a). Identification of trailer heat zones and associated heat stress in weaner pigs transported by road in tropical climates. Journal of Thermal Biology 97: 102882. DOI: https://doi.org/10.1016/j.jtherbio.2021.102882

Machado NAF, Costa LBS da, Barbosa-Filho JAD, Oliveira KPL de, Sampaio LC de, Peitoxo MSM, Damasceno FA (2021b). Using infrared thermography to detect subclinical mastitis in dairy cows in compost barn systems. Journal of Thermal Biology 97:102881. DOI: https://doi.org/10.1016/j.jtherbio.2021.102881

Mota-Rojas D, Broom DM, Orihuela A, Velarde A, Napolitano F, Alonso-Spilsbury, M (2020) Effects of human-animal relationship on animal productivity and welfare. Journal of Animal Behaviour and Biometeorology 8: 196-205. DOI: http://dx.doi.org/10.31893/jabb.20026.

Mota-Rojas D, Santiago-Roldán P, Pedraza EP, Rodríguez RM, Hernández-Trujillo L, Ortgea MET (2014) Stress factors in weaned piglet. Vetérinaria Mexico 45:37-51. Available:

http://www.scielo.org.mx/scielo.php?script=sci_arttext\&pi $\mathrm{d}=$ S0301-50922014000200005\&lng=es\&nrm=iso

Pereira TL, Titto EAL, Conte S, Devillers N, Sommavilla R, Diesel T, Dalla Costa FA, Guay F, Friendship R, Crowe T, Faucitano L (2018) Application of a ventilation fan-misting bank on pigs kept in a stationary trailer before unloading: Effects on trailer microclimate, and pig behaviour and physiological response. Livestock Science 216:67-74. DOI: https://doi.org/10.1016/j.livsci.2018.07.013

Perez MP, Palacio J, Santolaria MP, Aceña MC, Chacón G, Gascón M, Calvo JH, Zaragoza P, Beltran JA, GarcíaBelenguer S (2002) Effect of transport time on welfare and meat quality in pigs. Meat Science 61:425-33. DOI: https://doi.org/10.1016/S0309-1740(01)00216-9

Pinheiro DG, Barbosa-Filho JAD, Machado NAF (2020) Effect of wetting method on the broiler transport in Brazilian Northeast. Journal of Animal Behaviour and Biometeorology 8, 168-173. DOI: https://doi.org/10.31893/jabb.20022 
Pinheiro DG, Machado NAF, Barbosa Filho JAD, Silva IJO (2021) Computational Analysis of Load Ventilation in Broiler Transport. Engenharia Agricola 41: 9-18. DOI:

https://doi.org/10.1590/1809-4430-eng.agric.v41n1p9-18/2021

Rioja-Lang FC, Brown JA, Brockhoff EJ, Faucitano L (2019) A review of swine transportation research on priority welfare issues: A canadian perspective. Frontiers in Veterinary Science 6:1-12. DOI: https://doi.org/10.3389/fvets.2019.00036

Rocha LM, Velarde A, Dalmau A, Saucier L, Faucitano L (2016) Can the monitoring of animal welfare parameters predict pork meat quality variation through the supply chain (From farm to slaughter)? Journal Animal Science 94:359-376. DOI: https://doi.org/10.2527/jas.2015-9176

Rodrigues VC, da Silva I, Vieira F, Nascimento S (2011) A correct enthalpy relationship as thermal comfort index for livestock. International Journal of Biometeorology 55: 455-459. DOI: https://doi.org/10.1007/s00484-010-0344-y
SAS. 2012. SAS/STAT® 9.3 User's guide. Cary, SAS Institute.

Silva-Miranda KO, Borges G, Menegale VLC, Silva IJO (2012) Effects of environmental conditions on sound level emitted by piglets. Engenharia Agrícola 32: 435-455. DOI: http://dx.doi.org/10.1590/S0100-69162012000300003

Soerensen DD, Clausen S, Mercer JB, Pedersen LJ (2014) Determining the emissivity of pig skin for accurate infrared thermography. Computers and Electronics in Agriculture 109: 52-58. DOI:

https://doi.org/10.1016/j.compag.2014.09.003

Tasse ME, Molento CFM (2019) Injury and condemnation data of pigs at slaughterhouses with federal inspection in the state of Paraná, Brazil, as indicators of welfare during transportation. Ciência Rural 49:1-8. DOI: https://doi.org/10.1590/0103-8478cr20180243 